\title{
Analytical Approaches toward Successful Human Cell Metabolome Studies by NMR Spectroscopy
}

\author{
Iola F. Duarte, ${ }^{\dagger}$ Joana Marques, ${ }^{\dagger}$ Ana F. Ladeirinha, ${ }^{+}$Cláudia Rocha, ${ }^{\dagger}$ Inês Lamego, ${ }^{\dagger}$ \\ Rita Calheiros, $\$$ Tânia M. Silva,\$ M. Paula M. Marques, ${ }^{\S}$ Joana B. Melo, ${ }^{\ddagger}$ Isabel M. Carreira, ${ }^{\ddagger}$ and \\ Ana M. Gil*,t
}

CICECO-Departmento de Química, Campus Universitário de Santiago, Universidade de Aveiro, 3810-193 Aveiro, Portugal, Cytogenetics Laboratory and Center of Neurosciences and Cellular Biology, Faculty of Medicine, University of Coimbra, 3001-401 Coimbra, Portugal, and Research Unit "Molecular Physical-Chemistry", University of Coimbra, Portugal

The aim of this work was to investigate the effects of cell handling and storage on cell integrity and ${ }^{1} \mathrm{H}$ high resolution magic angle spinning (HRMAS) NMR spectra. Three different cell types have been considered (lung tumoral, amniocytes, and MG-63 osteosarcoma cells) in order for sample-dependent effects to be identified. Cell integrity of fresh cells and cells frozen in cryopreservative solution was $\sim 70-80 \%$, with the former showing higher membrane degradation, probably enzymatic, as indicated by increased phosphocholine (PC) and/or glycerophosphocholine (GPC). Unprotected freezing (either gradual or snap-freezing) was found to lyse cells completely, similar to mechanical cell lysis. Besides enhanced metabolites visibility, lysed cells showed a different lipid profile compared to intact cells, with increased choline, PC, and GPC and decreased phosphatidylcholine (PTC). Cell lysis has, therefore, a significant effect on cell lipid composition, making handling reproducibility an important issue in lipid analysis. Sample spinning was found to disrupt 5-25\% of cells, depending on cell type, and HRMAS was shown to be preferable to solution-state NMR of suspensions or supernatant, giving enhanced information on lipids and comparable resolution for smaller metabolites. Relaxation- and diffusion-edited NMR experiments gave limited information on intact cells, compared to lysed cells. The ${ }^{1} \mathrm{H}$ HRMAS spectra of the three cell types are compared and discussed.

Nuclear magnetic resonance (NMR) spectroscopy has been, in recent years, increasingly employed for the analysis of metabolic processes in biological systems because of its ability to provide rapid detection of many different metabolites present in complex systems such as biofluids, biological tissues, or cells. The analysis of the metabolome of biological systems provides important information on their biochemical phenotypes and on the metabolic

\footnotetext{
* To whom correspondence should be addressed. E-mail: agil@ua.pt.

${ }^{\dagger}$ CICECO-Departmento de Química, Campus Universitário de Santiago, Universidade de Aveiro.

₹ Cytogenetics Laboratory and Center of Neurosciences and Cellular Biology, Faculty of Medicine, University of Coimbra.

§ Research Unit "Molecular Physical-Chemistry", University of Coimbra.
}

changes occurring in response to external stimuli, e.g., drug exposure, disease onset, medication. ${ }^{1,2}$

The study of cellular metabolism using NMR has been successfully carried out with strong emphasis on cell extracts, either hydrophilic or lipophilic. For instance, acidic extracts, in the presence of ice-cold perchloric acid (PCA) or trichloroacetic acid (TCA), allow polar metabolites to be identified ${ }^{3,4}$ as shown for PCA extracts of human colon adenocarcinoma cells ${ }^{5}$ and human osteosarcoma cells $\mathrm{s}^{6,7}$ and TCA extracts of human rhabdomyosarcoma cells ${ }^{8}$ and human lung cancer cells. ${ }^{9}$ Other extraction methods have been used to identify aqueous and lipophilic metabolites, for instance in human colon carcinoma cells, ${ }^{10}$ rat astrocyte cells, ${ }^{11}$ human prostate cancer cells,${ }^{12}$ and human lung carcinoma cell lines. ${ }^{13}$ In addition to the unavoidable selectivity of extraction methods, rendered useful only when the nature of the compounds of interest is known a priori, sample extraction may involve significant loss of particular cellular components, retained in the residual insoluble precipitate and not amenable to study by solution-state techniques. ${ }^{14}$ Although significant advances have been made regarding efficiency and reproducibility of cell extraction procedures for metabonomics

(1) Lindon, J. C.; Nicholson, J. K.; Holmes, E.; Everett, J. R. Concepts Magn. Reson. 2000, 12, 289-320.

(2) Bollard, M. E.; Stanley, E. G.; Lindon, J. C.; Nicholson, J. K.; Holmes, E. NMR Biomed. 2005, 18, 143-162.

(3) Fan, T. W.-M.; Lane, A. N. Prog. Nucl. Magn. Reson. Spectrosc. 2008, 52, $69-117$.

(4) Fan, T. W.-M. Prog. Nucl. Magn. Reson. Spectrosc. 1996, 28, 161-219.

(5) Moreno, A.; Lopez, L. A.; Fabra, A.; Arus, C. NMR Biomed. 1998, 11, 93106.

(6) Santini, M. T.; Rainaldi, G.; Romano, R.; Ferrante, A.; Clemente, S.; Motta, A.; Indovina, P. L. FEBS Lett. 2004, 557, 148-154.

(7) Santini, M. T.; Romano, R.; Rainaldi, G.; Ferrante, A.; Motta, A.; Indovina, P. L. Radiat. Res. 2006, 165, 131-141.

(8) Lane, A. N.; Fan, T. W. M. Metabolomics 2007, 3, 79-86.

(9) Fan, T. W. M.; Bandura, L. L.; Higashi, R. M. Metabolomics 2005, 1, 325339.

(10) Chung, Y. L.; Troy, H.; Kristeleit, R.; Aherne, W.; Jackson, E.; Atadja, P.; Griffiths, J. R.; Judson, I. R.; Workman, P.; Leach, M. O.; Beloueche-Babari, M. Neoplasia 2008, 10, 303-313.

(11) Le Belle, J. E.; Harris, N. G.; Bhakoo, K. K. NMR Biomed. 2002, 15, 3744.

(12) Zhang, F.; Bruschweiler-Li, L.; Robinette, S. L.; Bruschweiler, R. Anal. Chem. 2004, 80, 7549-7553.

(13) Gottschalk, M.; Ivanova, G.; Collins, D. M.; Eustace, A.; O'Connor, R.; Brougham, D. F. NMR Biomed. 2008, 21, 809-819.

(14) Weybright, P.; Millis, K.; Campbell, N.; Cory, D. G.; Singer, S. Magn. Reson. Med. 1998, 39, 337-345. 
analysis, ${ }^{15}$ the direct study of cells has been increasingly preferred if a metabonomic approach is to be employed. This requires the characterization of the whole cellular metabolite profile, preferably under conditions in which the system is altered as little as possible, using simple reproducible sampling methods that allow for multivariate analysis to be employed for statistical validation of metabolic changes.

Solution-state ${ }^{1} \mathrm{H}$ NMR has often been employed to study intact human cells, such as osteosarcoma cells, ${ }^{6,7,16}$ lung carcinoma cells, ${ }^{13}$ erythroleukemic cells, ${ }^{17}$ and mammary carcinoma and colon adenocarcinoma cells. ${ }^{18}$ However, results generally give broad spectral profiles, with the gradual deposition of the cell suspension in the NMR tube, thus precluding the acquisition of long 2D experiments. High resolution magic angle spinning (HRMAS) ${ }^{1} \mathrm{H}$ NMR spectroscopy has, during the last 10 years, allowed significantly improved resolution to be achieved for tissues ${ }^{19-21}$ and cell samples. ${ }^{22-30}$ HRMAS has been successfully employed for the metabolic profiling of different types of tissues ${ }^{19-21}$ and has been increasingly applied to identify metabolic changes in mammalian cells, e.g., associated with cell type, ${ }^{22}$ differentiation, ${ }^{23}$ genetic modification, ${ }^{24,25}$ and response to drug exposure. ${ }^{26-28}$ As for biological tissues, most studies on cells have used freezing and storage at $-80{ }^{\circ} \mathrm{C}$ to preserve the cells prior to NMR analysis, generally working under the assumption that cell membrane integrity is retained. However, the action of freezing cells may involve some membrane damage, ${ }^{22}$ the effect of which in the metabolic profile, as viewed by NMR, needs to be taken into account. Some studies have also expressed concerns about the effects of NMR experimental parameters such as sample spinning $^{22,29}$ and temperature ${ }^{22,30}$ during spectral acquisition on cellular integrity. Indeed, the issue of cell integrity is determinant,

(15) Wu, H.; Southam, A. D.; Hines, A.; Viant, M. R. Anal. Biochem. 2008, 372, 204-212.

(16) Santini, M. T.; Romano, R.; Rainaldi, G.; Indovina, P.; Ferrante, A.; Motta, A.; Indovina, P. L. Radiat. Res. 2006, 166, 734-745.

(17) Knijn, A.; Brisdelli, F.; Ferretti, A.; Iorio, E.; Marcheggiani, D.; Bozzi, A. Cell Biol. Int. 2005, 29, 890-897.

(18) Santini, M. T.; Romano, R.; Rainaldi, G.; Filippini, P.; Bravo, E.; Porcu, L.; Motta, A.; Calcabrini, A.; Meschini, S.; Indovina, P. L.; Arancia, G. Biochim. Biophys. Acta 2001, 1531, 111-131.

(19) Wang, Y.; Holmes, E.; Comelli, E. M.; Fotopoulos, G.; Dorta, G.; Tang, H.; Rantalainen, M. J.; Lindon, J. C.; Corthesy-Theulaz, I. E.; Fay, L. B.; Kochhar, S.; Nicholson, J. K. J. Proteome Res. 2007, 6, 3944-3951.

(20) Rabeson, H.; Fauvelle, F.; Testykier, G.; Foquin, A.; Carpentier, P.; Dorandeu, F.; van Ormondt, D.; Graveron-Demilly, D. Magn. Reson. Med. 2008, 59, 1266-1273.

(21) Sitter, B.; Bathen, T. F.; Tessem, M.-B.; Gribbestad, I. S. J. Prog. Nucl. Magn. Reson. Spectrosc. 2009, 54 (3-4), 239-254.

(22) Griffin, J. L.; Bollard, M.; Nicholson, J. K.; Bhakoo, K. NMR Biomed. 2002, 15, 375-384.

(23) Shi, C.; Wang, X.; Zhu, Y.; Chung, L.; Mao, H. Exp. Hematol. 2007, 35, 28-29.

(24) Griffin, J. L.; Mann, C. J.; Scott, J.; Shoulders, C. C.; Nicholson, J. K. FEBS Lett. 2001, 509, 263-266.

(25) Peet, A. C.; McConville, C.; Wilson, M.; Levine, B. A.; Reed, M.; Dyer, S. A.; Edwards, E. C.; Strachan, M. C.; McMulan, D. J.; Wilkes, T. M.; Grundy, R. G. NMR Biomed. 2007, 20, 692-700.

(26) Borel, M.; Degoul, F.; Communal, Y.; Mounetou, E.; Bouchon, B.; CGaudreault, R.; Madelmont, J. C.; Miot-Noirault, E. Br. J. Cancer 2007, 96, 1684-1691.

(27) Morvan, D.; Demidem, A.; Papon, J.; Madelmont, J. C. Magn. Reson. Med. 2003, 49, 241-248.

(28) Chen, J.-H.; Enloe, B. M.; Weybright, P.; Campbell, N.; Dorfman, D.; Fletcher, C. D.; Cory, D. G.; Singer, S. Magn. Reson. Med. 2002, 48, 602610.

(29) Griffin, J. L.; Pole, J. C. M.; Nicholson, J. K.; Carmichael, P. L. Biochim. Biophys. Acta 2003, 1619, 151-158. as the extension of membrane degradation is expected to affect the resulting spectral profiles.

This work deals with the need to establish the sampling factors which influence cell integrity and NMR spectral quality, ranging from cell handling procedures to the NMR method chosen. A systematic approach is described to investigate the effects on the NMR spectra of cells of (a) manipulation in the fresh state, (b) direct or protected-freezing for storage, and (c) mechanical lysis, using three different human cell types: lung cells, amniocytes, and an osteosarcoma cell line (MG-63). These different types of cells are part of ongoing work to be published elsewhere, within different contexts, and their comparison in this work allows for any sample-dependent effects to be identified. In addition, the use of HRMAS is compared to standard solution-state NMR of cell suspensions and of the supernatants obtained after centrifugation, also addressing the issue of the effect of sample spinning and duration on cell integrity. The results obtained should help improved procedures for cell NMR studies to be established with regard to cell integrity and NMR data quality.

\section{EXPERIMENTAL SECTION}

Chemicals. Culture media (MEM), antibiotics (penicillin-streptomycin $100 \times$ solution), DMSO, fetal bovine serum (FBS), Trypan blue, trypsin, inorganic salts and acids (of analytical grade), choline, phosphocholine, and glycerophosphocholine were purchased from Sigma-Aldrich Chemical Co.

Samples. Three different types of human cells were used in this work: (1) Lung tumoral (LT) cells isolated from a human lung tumor biopsy, (2) amniocytes (AM) isolated from human amniotic fluid, and (3) MG-63 osteosarcoma cells kindly provided by the Associate Laboratory IBMC-INEB, Portugal. LT and AM cells were cultured in Ham's F10 medium supplemented with 15\% fetal bovine serum (LT) or $10 \%$ fetal bovine serum with $1 \%$ Ultroser (AM), while MG-63 cells were grown in Eagle's Minimum Essential Medium (MEM) supplemented with 10\% heat-inactivated fetal bovine serum, $1 \mathrm{mM}$ sodium pyruvate, nonessential amino acids, and antibiotics (penicillin-streptomycin 100x). All cells were maintained at $37{ }^{\circ} \mathrm{C}$ in a humidified atmosphere under $5 \% \mathrm{CO}_{2}$ and harvested upon addition of trypsin (0.05\% trypsin/EDTA solution) and centrifugation at $1100 \mathrm{rpm}$ for $5 \mathrm{~min}$. The pellets were washed with phosphate buffer solution (PBS, $\mathrm{pH}$ 7.4) and centrifuged at $1100 \mathrm{rpm}$ for $5 \mathrm{~min}$. The cells were resuspended in $1.5 \mathrm{~mL}$ of $\mathrm{PBS} / \mathrm{D}_{2} \mathrm{O}\left(\mathrm{NaCl}, 0.14 \mathrm{M} ; \mathrm{KCl}, 0.0027 \mathrm{M} ; \mathrm{KH}_{2} \mathrm{PO}_{4}\right.$, $0.0015 \mathrm{M} ; \mathrm{Na}_{2} \mathrm{HPO}_{4}, 0.0081 \mathrm{M}$ in deuterated water, $\mathrm{pH}$ 7.4). For each cell type, a pool of cells was divided into Falcon tubes in order to obtain a resuspension of $1.0-1.5 \times 10^{7}$ cells in each tube.

Then, according to the diagram depicted in Figure 1, different manipulation and storage procedures were employed, in order to test the effects of sample handling procedures on cell integrity and NMR profiles. The experimental procedures (shown as Supporting Information) were designed to ensure that all growth medium was replaced by $\mathrm{PBS} / \mathrm{D}_{2} \mathrm{O}$ and that no loss of cellular material occurred in any step of the method. Sample A1 is a cellular pellet obtained by washing the cells with phosphate buffer saline (PBS), followed by $\mathrm{PBS} / \mathrm{D}_{2} \mathrm{O}$, and characterized by HRMAS NMR within $2-3 \mathrm{~h}$ after harvesting, during which

(30) Li, W.; Lee, R. E. B.; Lee, R. E.; Li, J. Anal. Chem. 2005, 77, 5785-5792. 


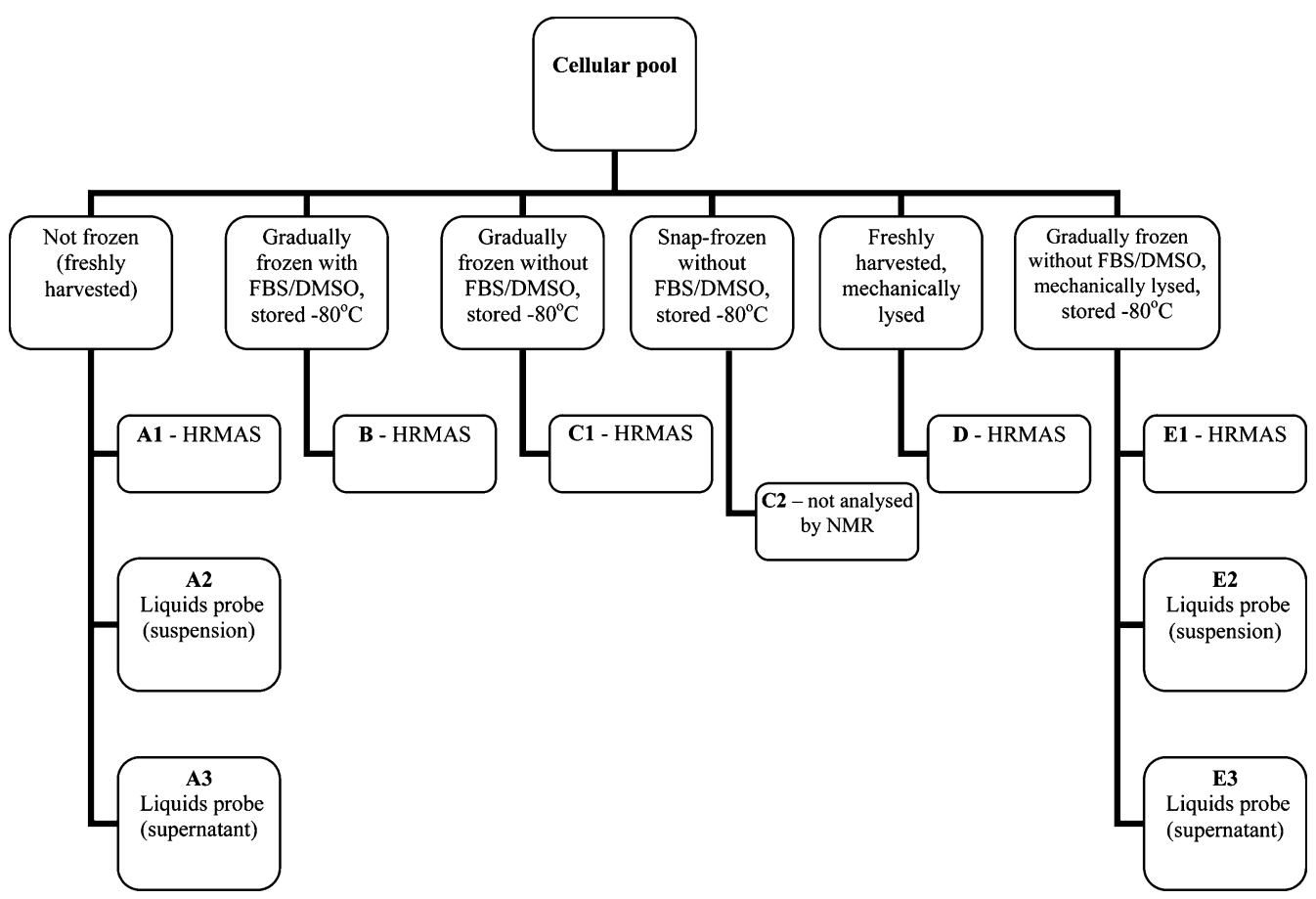

Figure 1. Schematic representation of the protocols followed for preparation of cell samples.

period the cells were kept refrigerated at $4{ }^{\circ} \mathrm{C}$. Sample A2 corresponds to a cellular suspension of $\mathbf{A 1}$ in $600 \mu \mathrm{L}$ of PBS/ $\mathrm{D}_{2} \mathrm{O}$, transferred into an NMR tube, and sample A3 is the supernatant of $\mathbf{A} 2$ removed from the NMR tube after cell deposition at the bottom (after acquisition of the spectrum for A2). Sample B was obtained by suspending the cells in a cryoprotective solution (fetal bovine serum, FBS with $10 \%$ DMSO) freezing and storing at $-80{ }^{\circ} \mathrm{C}^{31,32}$ for gradually $\sim 1$ month. Prior to NMR analysis, samples were thawed and washed with $\mathrm{PBS}$, followed by $\mathrm{PBS} / \mathrm{D}_{2} \mathrm{O}$. Samples $\mathrm{C}$ resulted from freezing the cell pellets (with gradual freezing for $\mathbf{C} \mathbf{1}$ and snap freezing for C2), without the cryoprotective agent, storing at $-80{ }^{\circ} \mathrm{C}$ for $\sim 1$ month, and thawing immediately prior to analysis. Both snap-freezing and a gradual freezing procedure were carried out for comparison (see Supporting Information), although the latter is preferably recommended for cellular viability to be maintained. Indeed, freezing is known to cause severe cellular damage if not performed carefully, due to intracellular ice crystals and osmotic effects. ${ }^{31,32}$ Cellular injury may be minimized by using a cryoprotective agent (as in sample B), coupled with a freezing rate of ca. $-1{ }^{\circ} \mathrm{C} / \mathrm{min}$ which is just slow enough to allow the cells time to dehydrate but fast enough to prevent excessive dehydration damage. ${ }^{31,32}$ Sample $\mathbf{D}$ was obtained by mechanical lysis of freshly harvested cells (refrigerated for up to $3 \mathrm{~h}$ ) through sonication and dipping into liquid nitrogen. Samples E1, E2, and E3 also correspond to lysed cells but for which the lysis procedure was performed after a period of $\sim 1$ month during which the cells were kept frozen at $-80^{\circ} \mathrm{C}$. After lysing, cell suspension $\mathbf{E} 1$ was prepared for HRMAS, whereas

(31) Culture of Animal Cells: A Manual of Basic Technique, 3rd ed.; Wiley-Liss: New York, 1994.

(32) Hay, R. J.; Miranda-Cleland, M. ; Durkin, S.; Reid, Y. A. In Practical Approach Series - Animal Cell Culture; Masters, J. R. W., Ed.; Oxford University Press: Cary, NC, 2000, pp 69-103. for samples E2 and E3, cell suspensions were mixed with 550 $\mu \mathrm{L}$ of $\mathrm{PBS} / \mathrm{D}_{2} \mathrm{O}$ and transferred into an NMR tube (sample E2) or centrifuged to obtain the supernatant (sample E3). With the exception of sample $\mathbf{E}$ of lung cells for which two replica essays have been carried out, no replica samples could be prepared for the remaining conditions because of practical difficulties in repeatedly producing at least 10 million cell pellets for NMR. However, the comparison between the three cell lines studied here will enable the reproducibility of the effects to be evaluated between cell types.

Trypan Blue Dye Exclusion Assay. The extent of cell death was assessed using the Trypan blue exclusion assay, which yields the number of living vs dead cells thus providing a measure of cell membrane integrity. ${ }^{33}$ Cells were incubated briefly with the Trypan blue dye $(0.4 \%(\mathrm{w} / \mathrm{v})$ solution in PBS) and were counted on a Neubauer-counting chamber. Cell viability was expressed as the percentage of living cells (dye-excluding) relative to the total number of cells (membrane-intact plus membrane disrupted cells) (mean \pm SEM, standard error of the mean). ${ }^{34}$

NMR Measurements. The cell pellets and suspensions (samples A1, B, C1, D, and E1), containing between 10 and 15 million cells, were packed into $50 \mu \mathrm{L}$ HRMAS rotors with $5 \mu \mathrm{L}$ of $\mathrm{D}_{2} \mathrm{O} / 3$-(trimethylsilyl) propionate sodium salt (TSP) $-d_{4} 0.25 \%$. ${ }^{1} \mathrm{H}$ NMR spectra were acquired on a Bruker Avance DRX-500 spectrometer operating at $500 \mathrm{MHz}$ for ${ }^{1} \mathrm{H}$ observation, at 293 $\mathrm{K}$, using a 4 mm HRMAS probe, in which the rotor containing the sample was spun at the magic angle at a spinning rate of $4 \mathrm{kHz}$. Typically, for each sample, three 1D experiments were acquired: (a) standard ${ }^{1} \mathrm{H}$ NMR spectrum with water suppression ('noesypr1d' in Bruker library, SW $6510 \mathrm{~Hz}$, TD $32 \mathrm{~K}$ data

(33) Durkin, W. S.; Ghanta, V. K.; Balch, C. M.; Davis, D. W.; Hiramoto, R. N. Cancer Res. 1979, 39, 402-407.

(34) Li, Y. L.; Lin, A. W.; Zhang, X. J.; Wang, Y. Q.; Wang, X. L.; Goodrich, D. W. Cancer Res. 2007, 67, 6657-6664. 
points, relaxation delay $4 \mathrm{~s}$, 256 scans), (b) $\mathrm{T}_{2}$-weighted (Carr-Purcell-Meiboom-Gill, CPMG) ${ }^{1} \mathrm{H}$ NMR spectrum to provide a clearer representation of low molecular weight metabolites ('cpmgpr' in Bruker library, total spin-spin relaxation $2 n \tau=90 \mathrm{~ms}$ ), and (c) diffusion-weighted ${ }^{1} \mathrm{H}$ NMR spectrum to select signals of bound or large molecules ('ledbpgp2s1dpr' in Bruker library, square gradients duration $2 \mathrm{~ms}$, gradient strength $48.15 \mathrm{G} \mathrm{cm}^{-1}$, diffusion time $200 \mathrm{~ms}$ ). Often, an additional standard spectrum was recorded after the series of three experiments in order to evaluate sample stability, showing that no degradation occurred over the course of the experiments (90 $\mathrm{min}$ at $293 \mathrm{~K}$ ). All 1D spectra were processed with a line broadening of $0.3 \mathrm{~Hz}$ and a zero filling factor of 2 , manually phased and baseline corrected. The chemical shifts were referenced internally to the alanine signal at $\delta 1.48$ (this peak was found to be more reliable than the TSP 0 ppm peak because of the sensitivity of the latter to compounds interacting with TSP). 2D homonuclear and heteronuclear spectra were registered for selected samples to aid spectral assignment. These included total correlation spectroscopy (TOCSY), heteronuclear single quantum coherence (HSQC), and J-resolved spectroscopy experiments. The ${ }^{1} \mathrm{H}$ NMR spectra of samples A2, A3, E2, and E3 were recorded with a broadband inverse (BBI) liquids probe using a standard 1D pulse sequence with water presaturation ('noesypr1d' in Bruker library, SW 6510 $\mathrm{Hz}$, TD $32 \mathrm{~K}$ data points, relaxation delay $4 \mathrm{~s}$, 256 scans). Spectral assignment was carried out with the support of Bruker Biorefcode spectral database, as well as of other existing databases $^{35,36}$ and specific compound standard solutions.

\section{RESULTS AND DISCUSSION}

Influence of Cell Integrity on NMR Spectral Profiles. The cells membrane integrity was evaluated for each cell type using the Trypan blue dye exclusion assay, just before and after NMR analysis, using the cells recovered from the HRMAS rotors. The data obtained for samples $\mathbf{A} \mathbf{1}$ and $\mathbf{B}$ (Table 1) indicated that, at the time of analysis, about $20-30 \%$ cells were cleaved in the pellets, either resulting directly from harvesting and refrigeration for up to $3 \mathrm{~h}$ (in A1) or after storage at $-80^{\circ} \mathrm{C}$ with cryoprotective agent (in B). Although affected by a large method-related error, the range of \% of cleaved cells was, as expected, shown to be cell type dependent with MG-63 cells being relatively less damaged. The cell counts also indicated that protective freezing in FBS/ DMSO is equally efficient in preserving cell integrity as using freshly harvested cells, kept briefly under refrigeration until analysis. Still, for procedures A and B, most cells remained intact, samples obtained through protective freezing presenting the advantage of easiness of storage over longer periods. However, care should be taken with the choice of cryoprotective agent in

(35) Wishart, D. S.; Tzur, D.; Knox, C.; Eisner, R.; Guo, A. C.; Young, N.; Cheng, D.; Jewell, K.; Arndt, D.; Sawhney, S,; Fung, C.; Nikolai, L.; Lewis, M.; Coutouly, M. A.; Forsythe, I.; Tang, P.; Shrivastava, S.; Jeroncic, K.; Stothard, P.; Amegbey, G.; Block, D.; Hau, D. D.; Wagner, J.; Miniaci, J.; Clements, M.; Gebremedhin, M.; Guo, N.; Zhang, Y.; Duggan, G. E.; MacInnis, G. D.; Weljie, A. M.; Dowlatabadi, R.; Bamforth, F.; Clive, D.; Greiner, R.; Li, L.; Marrie, T.; Sykes, B. D.; Vogel, H. J.; Querengesser, L. Nucleic Acids Res. 2007, 35 (Database issue), D521-6. http://www.hmdb.ca.

(36) Seavey, B. R.; Farr, E. A.; Westler, W. M.; Markley, J. L. J. Biomol. NMR 1991, 1, 217-236. (http://www.bmrb.wisc.edu/metabolomics/ metabolomics_standards.html).

\section{Table 1. Percentage of Living Cells As Determined by the Trypan Blue Exclusion Assay (number of counts for each batch $=2-4$; SEM = standard error of the mean; n.d. = not determined because of technical problem)}

\begin{tabular}{ccccccc} 
& & \multicolumn{2}{c}{ before HRMAS } & & \multicolumn{2}{c}{ after HRMAS } \\
cell type & sample $^{a}$ & mean & SEM & & mean & SEM \\
LT & A1 & 67.9 & 0.8 & & 45.0 & 5.4 \\
& B & 67.6 & 0.2 & & 53.5 & 1.4 \\
AM & A1 & n.d. & n.d. & & 77.4 & 6.1 \\
& B & 76.6 & 0.8 & & 50.1 & 6.1 \\
MG-63 & A1 & 80.3 & 0.2 & & 74.7 & 1.7 \\
& B & 74.4 & 3.8 & & 79.9 & 0.1
\end{tabular}

${ }^{a}$ Samples $\mathbf{A 1}$ and $\mathbf{B}$ correspond to the procedures indicated in Figure $1 .{ }^{1} \mathrm{H}$ HRMAS NMR was carried out at $293 \mathrm{~K}$, using a $4 \mathrm{kHz}$ spinning rate during approximately $2 \mathrm{~h}$.

order for it not to hinder NMR analysis in the spectral regions of interest, and this will be discussed below. Samples C, D, and E (Figure 1) give information, respectively, on unintentional cell lysis by unprotected freezing and storage at $-80{ }^{\circ} \mathrm{C}$, the extent of mechanical lysis using a snap-freezing/sonication procedure, and the cumulative effects of freezing, storage at $-80{ }^{\circ} \mathrm{C}$ and mechanical lysis. All of these procedures produced cells which showed total staining with Trypan blue, indicating total membrane disruption. Interestingly, the results obtained for samples $\mathbf{C 1}$ and $\mathbf{C 2}$ (Figure 1) showed that unprotected freezing, including snapfreezing (a method used previously in handling intact cells for NMR analysis $\left.{ }^{22,24}\right)$, compromises cell integrity.

The effects of sample spinning rate and duration on cell integrity are factors of recognized importance in data quality, investigated previously for preadipocyte and adipocyte cells ${ }^{14}$ and for neuronal cells. ${ }^{22}$ The Trypan blue test has hereby shown that the behavior of cells spun at $4 \mathrm{kHz}$ during approximately $2 \mathrm{~h}$ depends significantly on cell type (Table 1). Indeed, LT and AM cells showed up to $25 \%$ cell breakage whereas the integrity of MG63 cells was not greatly affected. This indicated that each cell study should entail a prior investigation and optimization of sample spinning conditions if preservation of cell integrity is intended over the time of the experiment.

Figure 2 shows the high frequency $(\delta$ 8.8-5.5) and low frequency $(\delta 3.5-0.5)$ regions of the ${ }^{1} \mathrm{H}$ HRMAS standard spectra obtained for lung tumoral (LT) cells subjected to procedures A1, B, C1, D, and E1 (Figure 1 and Supporting Information). In the case of samples $\mathbf{C}$, only $\mathbf{C} \mathbf{1}$ (gradual freezing) was studied by NMR. Although all spectral profiles are dominated by broad lipid resonances, the three bottom spectra, corresponding to fully lysed cells, show many additional sharp signals arising from metabolites released from the intracellular shell. In the spectrum of sample $\mathbf{B}$, there is an intense singlet signal from residual DMSO $(\delta$ 2.73), used in the cryoprotective solution and not totally removed by washing once with $\mathrm{PBS}$ and $\mathrm{PBS} / \mathrm{D}_{2} \mathrm{O}$. With a second wash, the DMSO signal was found to decrease by about $90 \%$ without further breaking the cells. The FBS solution used here contains many different components (albumin and smaller metabolites); however, its contribution to the spectrum was found to be negligible, as the intensity of the interfering peaks was below the intensity of the ${ }^{13} \mathrm{C}$ satellites of the DMSO signal and, thus, much lower than the cells metabolite signals. The 


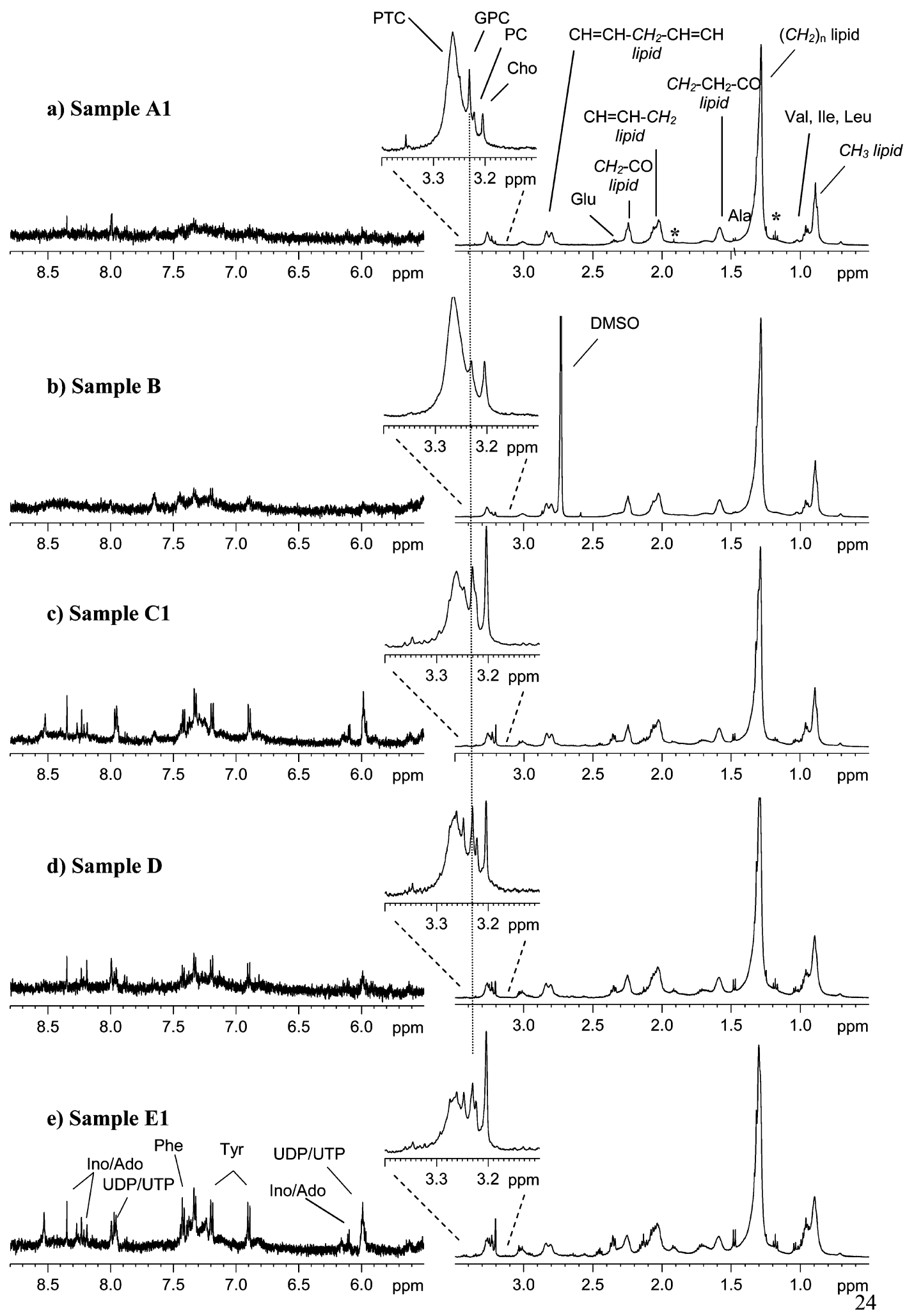

Figure 2. High frequency and low frequency regions of the $500 \mathrm{MHz}{ }^{1} \mathrm{H}$ HRMAS NMR spectra (NS 256) of lung tumoral (LT) cells: (a) freshly harvested and kept refrigerated for a few hours before analysis (sample $\mathbf{A}$ ), (b) frozen in FBS/DMSO and stored at $-80^{\circ} \mathrm{C}$ for 1 month (sample B), (c) frozen without cryopreservative and stored at $-80^{\circ} \mathrm{C}$ for 1 month (sample C), (d) mechanically lysed soon after harvesting (sample D), (e) mechanically lysed after storage at $-80^{\circ} \mathrm{C}$ for 1 month (sample E). The vertical dashed line is used to guide the eye.

sharp signals noted with an asterisk result from a PBS solution contaminant (an ethanol- and glycerol-containing mixture). Apart from this, it is clear that the standard ${ }^{1} \mathrm{H}$ HRMAS spectral profiles of samples A1 and B of LT cells are generally similar, revealing a dominant lipids profile (probably comprising contributions from both membrane and/or intracellular lipids ${ }^{37}$ )

(37) Hakumaki, J. M.; Kauppinen, R. A. TIBS 2000, 25, 357-362. 
a)

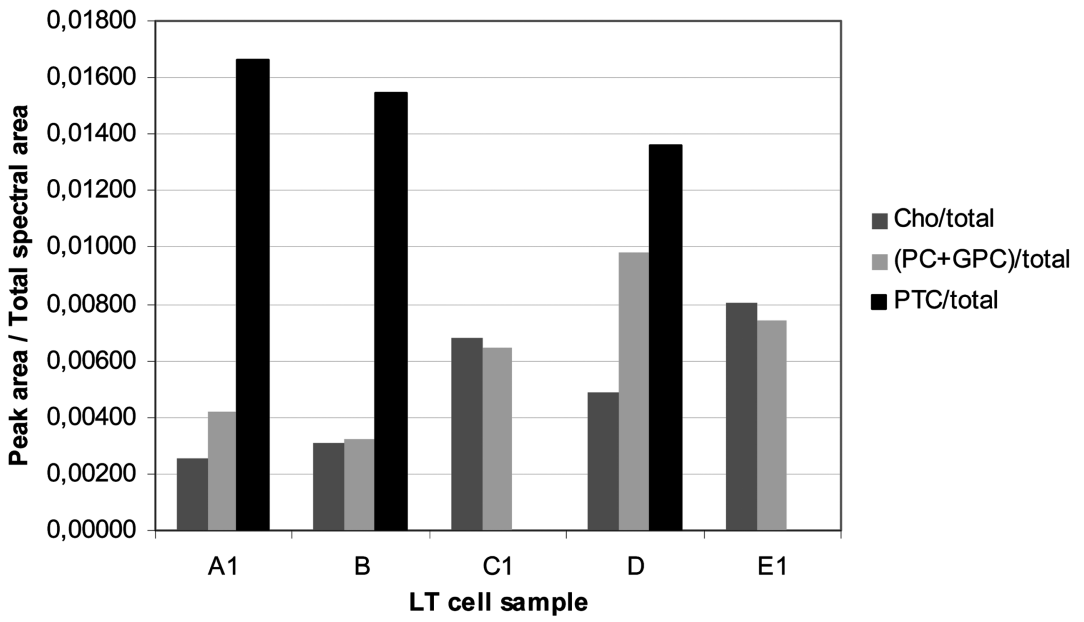

b)

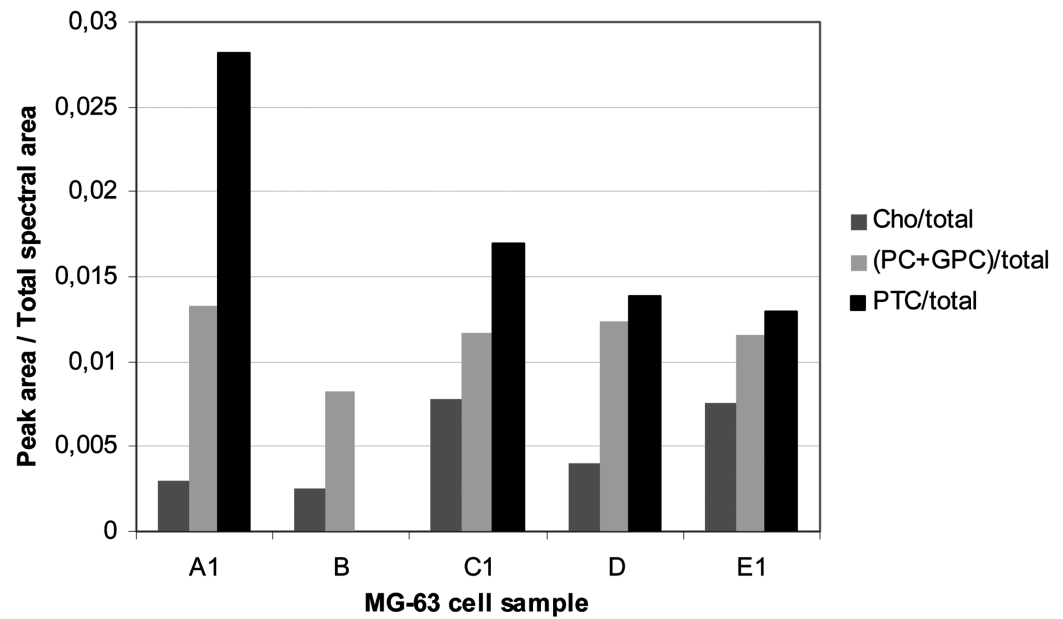

c)

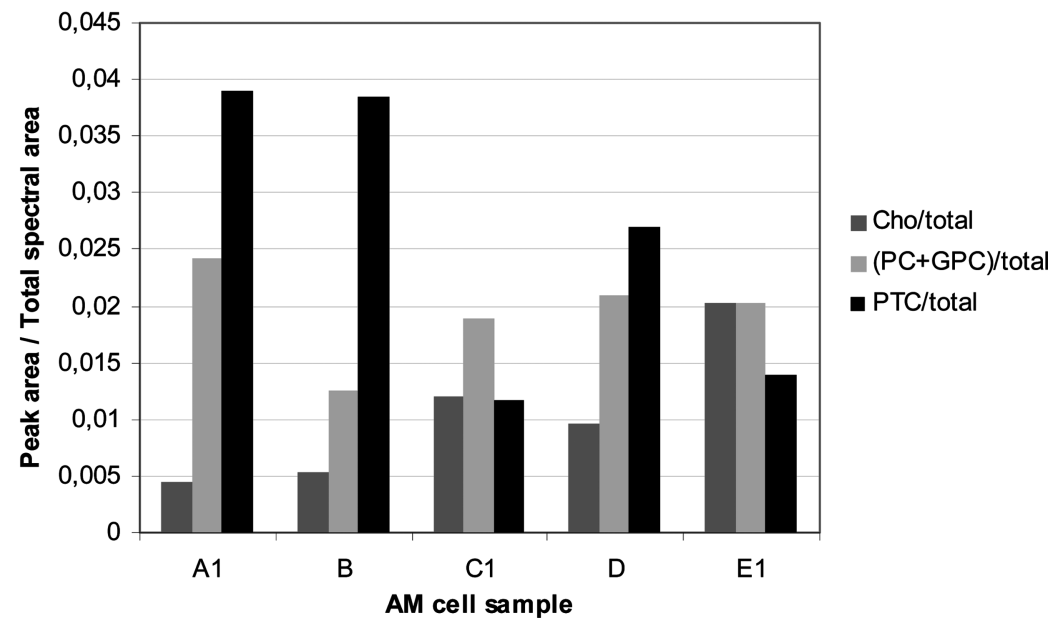

Figure 3. Integral values obtained for selected choline-containing compounds (cho $\delta 3.20, \mathrm{PC} \delta 3.22$, GPC $\delta 3.23$, PTC $\delta 3.26$ ) relative to total spectral area in the standard 1D spectra of (a) LT cells, (b) MG-63 cells, and (c) AM cells. The PTC integrals were measured in the diffusionedited spectra, because of severe overlap in the standard 1D spectra; as the diffusion experiment was not acquired for every sample, some integral values are missing in the graphs. Error bars are not shown, and the explanation for this may be found in the text.

and some additional information on cellular metabolites, with broadened signals being observed for alanine, valine, leucine, isoleucine, and a few others. However, the inserts in Figure 2 show that the intensities of $\mathrm{N}\left(\mathrm{CH}_{3}\right)_{3}{ }^{+}$resonances of cholinecontaining compounds change between samples $\mathbf{A} \mathbf{1}$ and $\mathbf{B}$ of LT cells, with glycerophosphocholine (GPC, $\delta$ 3.23) and phosphocholine (PC, $\delta$ 3.22) peaks being higher in $\mathbf{A 1}$ in relation to choline, compared to $\mathbf{B}$. Assignments were verified by running spectra of standard compounds choline, PC, and GPC. Indeed, the integral of the region comprising PC and GPC signals normalized to the total spectral area is higher in $\mathbf{A}$ than in $\mathbf{B}$ (Figure 3a). This difference is even more marked in MG-63 and AM cells (Figure 3b,c). It is recalled here that no error bars may be shown because of the difficulty in performing 

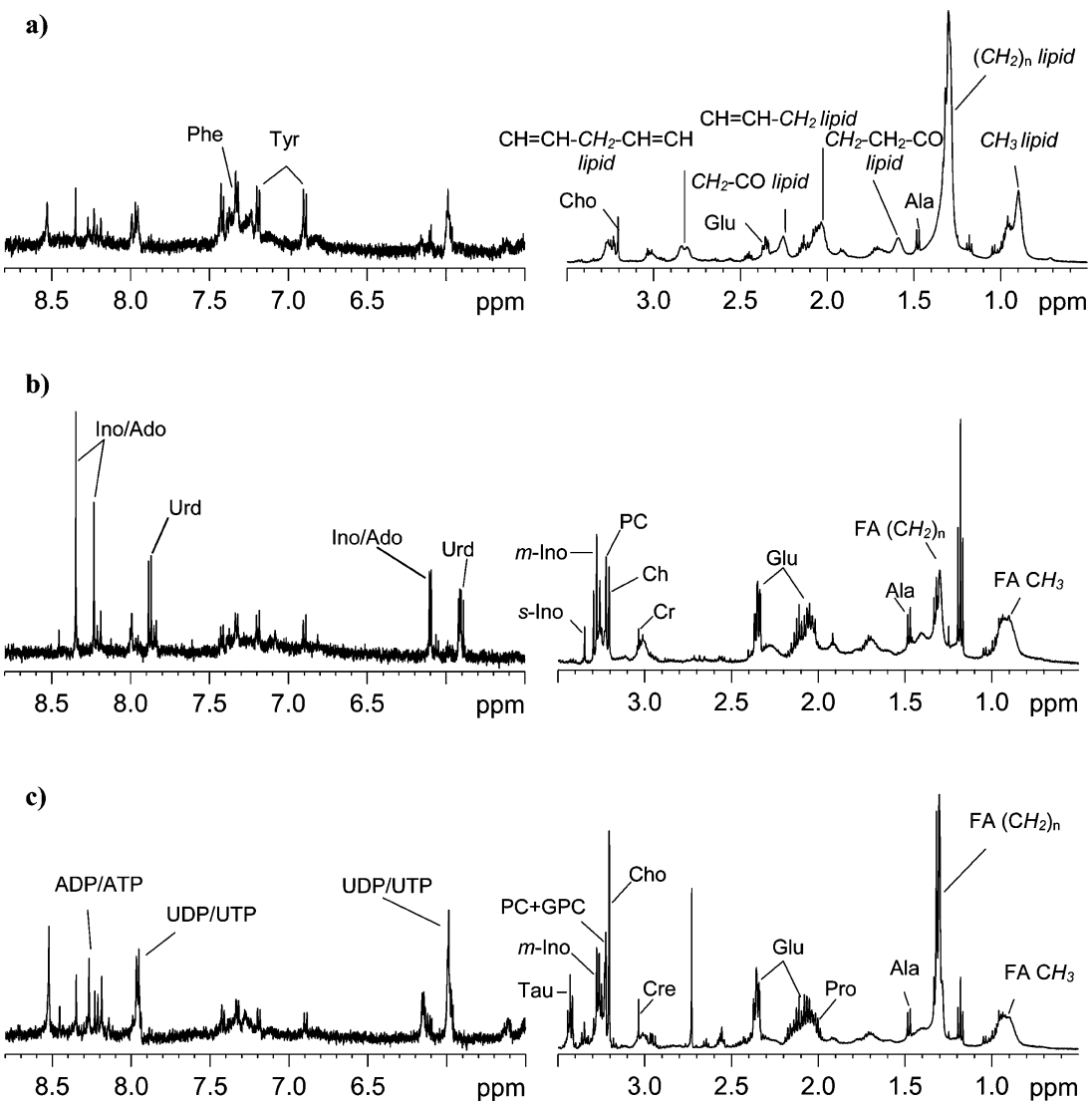

Figure 4. The $500 \mathrm{MHz}$ standard ${ }^{1} \mathrm{H}$ HRMAS spectra (NS 256) of fully lysed (a) lung tumoral (LT), (b) MG-63 cells, and (c) amniocytes (AM).

replicate assays with a sufficiently high number of cells for NMR analysis (at least 10 million). However, comparison between cell lines (Figure 3) aids in evaluating reproducibility between cell types. GPC and PC are membrane breakdown products, and their higher contents in samples A1 suggest higher membrane degradation, compared to samples $\mathbf{B}$. An increase in PC due to cell membrane disruption has been reported previously. ${ }^{24}$ In sample A1, this may arise because of the activity of degrading enzymes during the $2-3 \mathrm{~h}$ refrigeration period between harvesting and NMR analysis, showing how sensitive cell membranes are to sample handling. Interestingly, choline content (evaluated by the area of its headgroup signal divided by the total spectral area) is similar between samples A1 and B for all cell types (Figure 3). In addition, PTC integrals (measured in the diffusion-edited spectra because of severe overlap in the standard 1D spectra) remain high for both $\mathbf{A}$ and $\mathbf{B}$ samples, reflecting the maintenance of cell integrity for the majority of cells. These results show that, despite equivalent results given by the Trypan blue test for samples A1 and B (Table 1), the NMR lipid profiles indicate that cell membranes are less degraded in the case of samples cryoprotected with FBS/DMSO after harvesting (sample B), compared to fresh samples (sample A1).

The study of samples $\mathbf{C}$ gives insight on the effect of cell freezing without the use of a cryoprotective agent. The results given by the Trypan blue exclusion assay have shown that all cells are cleaved in the process, similar to samples $\mathbf{D}$ and $\mathbf{E}$ for which a cell lysis method was intentionally applied. The spectra in Figure 2c,d,e for samples $\mathbf{C 1}$ (stored at $-80{ }^{\circ} \mathrm{C}$ after gradual freezing without a cryoprotective agent), D (freshly harvested cells, intentionally lysed), and $\mathbf{E}$ (cells frozen and stored at $-80^{\circ} \mathrm{C}$ and intentionally lysed) of LT cells all reveal additional sharp lines arising from released inner cell metabolites. In addition, the profile from choline-containing compounds is changed, and it is noted that choline and PC $+\mathrm{GPC}$ increase for all lysed LT cells, relative to samples A1 and $\mathbf{B}$ (Figure 3a). Choline ( $\delta 3.20)$ increases in the order: sample $\mathbf{D}<$ sample $\mathbf{C} \mathbf{1}<$ sample $\mathbf{E} \mathbf{1}$, expressing, respectively, increase factors of 2.0, 2.7, and 3.2 relative to sample A1. On the other hand, the normalized $\mathrm{PC}+\mathrm{GPC}$ integrals give the highest value for sample $\mathbf{D}$ (lowest choline content), thus suggesting that choline may arise, at least partially, from PC and GPC degradation. In addition, the decrease in PTC (Figures 2 and 3) is also consistent with membrane degradation and PTC conversion to PC, GPC, and choline. In the case of MG-63 and AM cells, choline also increases markedly as a consequence of cell lysis and shows a variation within lysed samples (C, D, and E1) similar to that described for LT cells (Figure 3b,c). In these cell types, the PC+GPC increase in lysed cells is only noted relative to samples $\mathbf{B}$ (suggested to be the less degraded of all), with similar values to those found for sample A (Figure 3b,c). The decrease in PTC is also confirmed although, as the diffusion experiment was not acquired for every sample, some integral values are missing in the graphs. Thus, it seems fair to suggest that choline and/or PC+GPC to PTC ratios may be used as general indicators of the extension of cell physical breakage. Taking choline as the final end-product of cell choline-containing lipids, comparison between samples suggests, therefore, that unprotected freezing (sample C1) may have a more disruptive effect than intentional mechanical lysis (sample D), with the 
a)

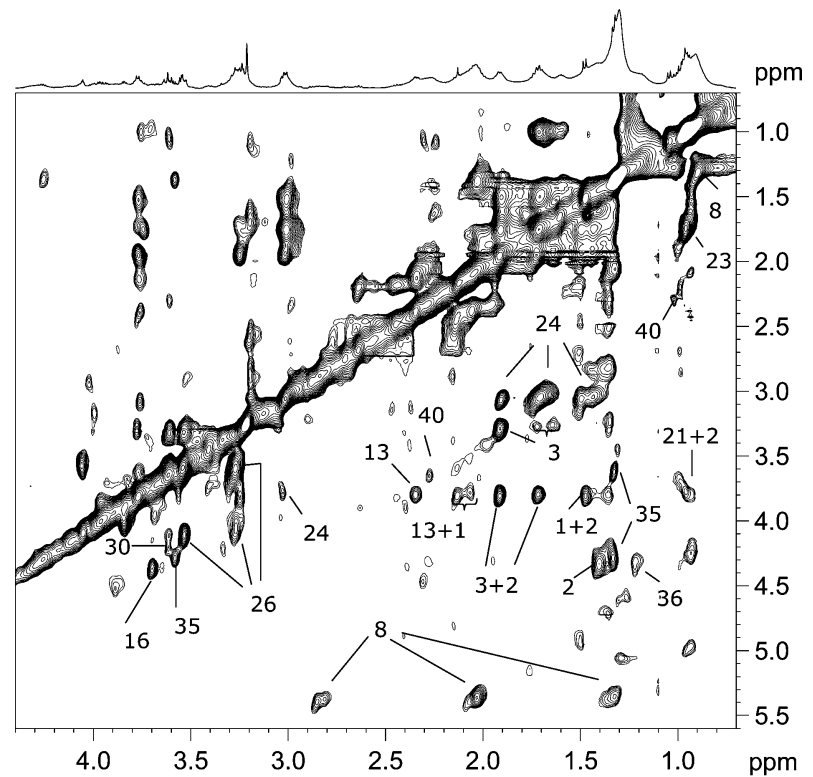

b)

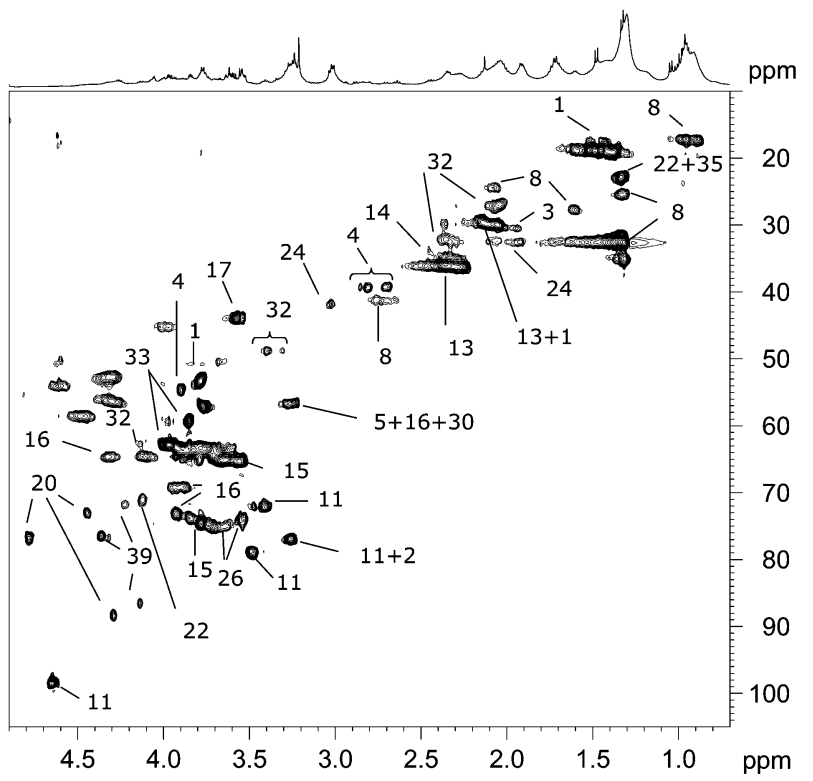

Figure 5. Expansions of $500 \mathrm{MHz} 2 \mathrm{D}$ (a) TOCSY and (b) HSQC spectra of fully lysed MG-63 cells. Numbering of peaks refers to the assignments listed in Table 2.

cumulative effects (sample E1) giving the highest cell breakage extension. As noted above, in fresh cells (samples A1), where cell breakage occurs to a much lesser extent, and possibly in parallel with membrane enzymatic degradation, GPC and PC contents seem to be better degradation indicators.

If lysed cells are to be considered for metabolome evaluation, then the reproducibility of the lysis procedure applied is an important issue. This was probed for two samples E1 of lung cells (data not shown), and although the corresponding NMR profiles are generally similar, choline and ethanol were found to vary showing, respectively, variations of 13 and $15 \%$. These variations are however relatively small, compared to the $45-75 \%$ variations obtained for choline between LT sample A and LT samples D, C, and $\mathbf{E}$. Nevertheless, a more systematic evaluation of lysis reproducibility is needed, and this has to be taken into account for metabonomic studies.
Table 2. Assignment of the 500 MHz 1D and 2D HRMAS NMR Spectra of Fully Lysed MG-63 Osteosarcoma Cells

$\begin{array}{ll}1 & \text { alanine } \\ 2 & \text { alanine (bonded) } \\ 3 & \text { arginine } \\ 4 & \text { asparagine/aspartate } \\ 5 & \text { choline } \\ 6 & \text { creatine } \\ 7 & \text { cytidine } \\ 8 & \text { fatty acyl chains (lipids) } \\ & \\ 9 & \text { formate } \\ 10 & \text { fumarate } \\ 11 & \text { glucose }\end{array}$

$\begin{array}{ll}12 & \text { glutathione } \\ 13 & \text { glutamate } \\ 14 & \text { glutamine } \\ 15 & \text { glycerol } \\ 16 & \text { glycerophosphocholine }\end{array}$

17 glycine

18 histidine

19 hypoxanthine

20 inosine

21 isoleucine

22 lactate

23 leucine

24 lysine

25 methionine

26 myo-inositol

27 niacinamide

28 phenylalanine

29 phosphatidylcholines

30 phosphocholine

31 phosphoethanolamine

32 proline

33 serine

34 taurine

35 threonine

36 threonine (bonded)

37 tyrosine

38 uracil

39 uridine

40 valine

$\delta{ }^{1} \mathrm{H}(\mathrm{ppm}) / \delta{ }^{13} \mathrm{C}(\mathrm{ppm})$

1.48 (d) $/ 18.703 .78 / 53.17$

1.414 .31

1.69 1.92/30.39 3.24 3.77

$2.69 / 39.122 .83 / 39.123 .89 / 54.51$

3.21 (s)/56.42 3.54/69.32 4.08/58.18

$3.03(\mathrm{~s}) 3.93(\mathrm{~s})$

$5.916 .06(\mathrm{~d}) 7.83(\mathrm{~d})$

0.88-0.95/17.07 1.31/25.28,32.38,

34.91 1.60/27.65 2.03/24.28 2.28

2.74/41.13 5.33/132.44

$8.46(\mathrm{~s})$

$6.52(\mathrm{~s})$

3.25/76.82 3.40/71.99 3.48/78.73

$3.53 / 73.973 .71 / 74.963 .76,3.88 / 63.26$

$3.85 / 73.514 .64(\mathrm{~d}) / 98.455 .23(\mathrm{~d}) /$

94.63

2.162 .57

2.09/29.63 2.36/35.96 3.77/56.92

$2.15 / 28.802 .45 / 33.683 .79 / 56.92$

$3.57 / 65.163 .66 / 65.163 .77 / 74.50$

$3.24(\mathrm{~s}) / 56.513 .65 / 64.943 .91 /$

$69.063 .92 / 73.08$ 4.32/64.48

$3.56(\mathrm{~s}) / 43.82$

$7.18(\mathrm{~s}) 8.12(\mathrm{~s})$

$8.18(\mathrm{~s}) 8.21(\mathrm{~s})$

4.29/88.18 4.44/73.04

4.78/76.64 6.11(d)/90.86 8.23(s)/

$148.538 .36(\mathrm{~s}) / 142.95$

0.95(t) $1.01(\mathrm{~d}) 1.99$

1.33 (d) $/ 22.704 .13$ (q) $/ 71.25$

0.95 (d) $/ 23.410 .97$ (d) 1.713 .76

$1.481 .721 .91 / 32.44$

$3.03 / 41.763 .78(\mathrm{t}) / 56.92$

2.13(s) 2.152 .65

$3.28 / 76.823 .54 / 73.38$

$3.62 / 74.504 .07 / 74.50$

7.598 .718 .94

$3.153 .293 .99 / 58.84$

7.32/131.81 7.38 7.43

$3.27(\mathrm{~s}) / 56.64$

$3.22(\mathrm{~s}) / 56.513 .624 .18$

$3.25 / 43.133 .97 / 63.02$

$2.04 / 26.902 .09 / 32.23$

2.36/32.23 3.36/48.67 4.10(t)/64.50

$3.84 / 59.113 .96 / 62.76$

$3.29(\mathrm{t}) 3.43(\mathrm{t})$

$1.33(\mathrm{~d}) / 22.703 .60(\mathrm{~d}) / 63.114 .29$

1.224 .29

$3.053 .183 .95 / 59.206 .89(\mathrm{~d}) /$

$118.287 .19(\mathrm{~d})$

$5.80(d) 7.53(d)$

4.14/86.24 4.23/71.72 5.89(d)

$5.92(\mathrm{~d}) / 91.857 .89(\mathrm{~d}) / 144.38$

0.98(d) 1.04 (d) $2.293 .63(\mathrm{~d})$

NMR of Intact Cells. In order to retrieve compositional information on intact cells, the 1D edited experiments, CPMG and diffusion-edited, may be attempted for detecting, respectively, small metabolites and larger, slow-diffusing compounds such as lipids. Figure S1 shows the three experiments obtained for sample B of LT cells, with the standard spectrum (Figure S1a) showing a dominant lipid profile. The CPMG experiment (Figure S1b) attenuates some of the broader signals of fast relaxing lipids $(\delta$ $0.70,1.02,1.58,2.24$, and 3.26 ), such as PTC, resulting in relatively enhanced visibility of small metabolites at around $1 \mathrm{ppm}$, where valine and isoleucine resonate, and at 3.1-4.0 ppm, where arginine, myo-inositol, glutamate/glutamine, and glycine resonances are observed. However, other lipid signals arising from methyl, methylene, allylic, and olefinic protons of fatty acyl chains 
$(\delta 0.89,1.28,2.03,2.82,5.33)$ are not significantly attenuated, consistently with the fact that, even in aggregate form, cellular lipids may be characterized by relatively high molecular mobility, especially if comprising unsaturated chains. The attenuation of different lipid signals to different extents in the CPMG experiment has been previously reported, for instance in the case of HRMAS NMR of endometrial cells, where methyl and methylene lipid resonances could be observed even with large spin echo delays of $320 \mathrm{~ms}^{29}$ The diffusion-edited spectrum shown in Figure S1c selects the lipids with more restricted mobility but does not add significant information to that obtained with a basis on the standard spectrum, since both spectra are dominated by cellular lipids profile. These observations were noted for all cell types investigated.

Bearing in mind that solution-state NMR is still generally more readily available than the HRMAS technique, the information provided by both methods on the intact cells was compared. Figure $\mathrm{S} 2$ shows the profiles obtained by direct analysis of sample A of MG-63 cells by ${ }^{1} \mathrm{H}$ HRMAS (sample A1 in Figure 1) and by solution-state ${ }^{1} \mathrm{H}$ NMR of both the cell suspension (A2) and the supernatant removed after deposition of the cells (A3). The corresponding spectra show that, as expected, the lipid profile is improved by the HRMAS technique, followed by the cell suspension spectrum. The lower signal-to-noise $(\mathrm{S} / \mathrm{N})$ ratio of the latter spectrum is due to the enhanced dilution of the sample, being expected to degrade overtime because of sample deposition in the tube. Interestingly, the spectrum obtained for the supernatant (Figure S2c) of sample A (fresh cells with about $20 \%$ Trypan blue staining) is very similar to that of the corresponding suspension, indicating that metabolites leaked from the small percentage of broken cells, thus showing that significant metabolite loss may occur when supposedly intact cells pellets are washed and their metabolome analyzed. It is therefore important to address the reproducibility of the sampling method and take into account eventual metabolite losses even when mostly intact cells are considered.

NMR of Lysed Cells and Spectral Assignment. In cases where cell metabolome characterization is intended at a fixed point in time, the use of fully lysed cells is recommended since enhanced metabolic information is obtained, as shown above. In this case, the different 1D experiments show more marked differences between the CPMG and the diffusion-edited spectrum (Figure S3 in Supporting Information shows the example recorded for sample $\mathbf{D}$ of tumoral lung cells), the latter being particularly useful for information on the lipid components to be obtained.

In addition, the use of different NMR methods has shown that the corresponding spectra (not shown) of fully lysed cells (samples E1, E2, and E3) are significantly similar, both in terms of resolution and of the metabolic profiles detected, the main difference being that, as expected, lipid signals are enhanced in the HRMAS spectrum (E1) and hardly detected in the supernatant measured by solution-state NMR (E3). A lipid profile is also observed for the cellular suspension (E2), but the gradual deposition with time renders this option inadequate for lipid characterization. Since the fine detail of the small metabolites profile are expected to be sensitive to the sample handling conditions, great care must be taken in metabonomic studies in order to ensure suitable reproducibility for sampling of fully lysed samples. Interestingly, the spectral resolution observed for small metabolites in the HRMAS spectra, e.g., of MG-63 cells, was found to be comparable to that obtained for corresponding cell extracts (data not shown), which demonstrates the promise of HRMAS NMR of fully lysed cells compared to extract analysis.

Figure 4 shows the standard ${ }^{1} \mathrm{H}$ HRMAS spectra of the three types of cells studied here, in the fully lysed state (samples E1). The high spectral complexity enables extensive signal assignment by 2D NMR (Figure 5) and a reasonable picture of the cell metabolome to be obtained. It is interesting to note the distinctive profiles of each cell type. In particular, LT cells have significantly higher intensity of the broad signals from fatty acyl chains. This is explained by a greater triglyceride content, visible through the relatively higher glyceryl backbone signals $(\delta 4.08$, 4.28 , and 5.22) in LT cells, and also, probably, by higher fatty acid chain mobility due to higher chain unsaturation, as suggested by a stronger olefinic resonance at $5.33 \mathrm{ppm}$ (not shown). In addition, some metabolites are distinctly present in each cell type, namely uridine in MG-63, UDP/UTP in LT and AM, taurine and proline in AM, and myo-inositol in AM and MG-63 (being much less abundant in LT cells). The corresponding 2D NMR spectra have been assigned, enabling typical metabolic profiles to be established for the cells under study. As an example, Table 2 summarizes the main resonances identified for MG-63 cells, whereas the composition of the remaining cell types will be published in other contexts.

\section{CONCLUSIONS}

The effects of cell handling and storage on cell integrity and ${ }^{1} \mathrm{H}$ high resolution magic angle spinning (HRMAS) NMR spectral profiles have been systematically investigated for three different types of human cells (lung tumoral, amniocytes, and MG-63 osteosarcoma cells). Cell integrity of fresh cell pellets and of cells frozen in the presence of a cryoprotective agent was found to be highly preserved $(70-80 \%)$, with the former showing higher membrane degradation, probably of an enzymatic nature, as suggested by increased $\mathrm{PC}+\mathrm{GPC}$ compared to choline. However, even in these samples, significant metabolite loss is noted through the analysis of the pellet supernatant.

Conversely, freezing (either snap-freezing or gradual freezing) in the absence of a cryoprotection agent was found to cause total cell lysis, again for all cell types tested, similar to the effects of intentional mechanical cell lysis. The cell freezing protocol is, therefore, determinant for the integrity of cell samples, which was found to be maintained only when a gradual freezing protocol is performed, in the presence of a cryoprotective solvent (e.g., FBS/ DMSO). Interestingly, lysed cells (unintentionally or mechanically) showed a different spectral profile regarding cholinecontaining lipids as compared to fresh and cryopreserved cells, with marked increases in choline and $\mathrm{PC}+\mathrm{GPC}$ and significant decreases in PTC. Regarding the effect of spinning rate and duration, it was found that between 5 and $25 \%$ of cells were disrupted for $4 \mathrm{kHz}$ rates during $2 \mathrm{~h}$, the result being significantly dependent on cell types. In relation to NMR methods, the HRMAS method was, unsurprisingly, shown to be preferable to solutionstate NMR analysis of cell suspensions or supernatant, in all cases, allowing valuable information to be obtained both for lipids and low $M_{\mathrm{w}}$ metabolites. In addition, CPMG and diffusion-edited 
NMR experiments gave limited information when applied to intact cells, compared to fully lysed cells. Finally, the HRMAS spectra of the three types of cells, fully lysed for enhanced resolution, were compared and distinctive peaks identified, laying the basis for ongoing metabonomics work to be reported elsewhere.

This work has demonstrated that cell handling for NMR analysis requires enhanced care since the nature and extension of cell membranes degradation and disruption have important effects on cellular lipids composition. Furthermore, the reproducibility of the sampling method is of extreme importance if metabonomics is to be carried out, either with intact or with fully lysed cells, and its evaluation in terms of the NMR-visible cell metabolome is strongly recommended.

\section{ACKNOWLEDGMENT}

Funding is acknowledged from the Foundation for Science and Technology, Portugal, through the research projects FCT/PTDC/ SAU-BEB-66896/2006 and FCT/PTDC/QUI-68017/2006, and also from CIMAGO, University of Coimbra (project 14/06). The authors also acknowledge Dr. Manfred Spraul from Bruker BioSpin, Germany, for access to a comprehensive compound database for NMR assignment. The authors thank the Associate Laboratory IBMC-INEB (Portugal) for having provided the MG63 osteosarcoma cell line.

\section{SUPPORTING INFORMATION AVAILABLE}

Step-by step description of the protocols used for preparation of all cell samples (A to $\mathbf{E}$ ). In addition, figures are shown to illustrate the (a) effect of different NMR experiments (1D standard, CPMG and diffusion edited) on the 1H HRMAS NMR spectra of intact lung tumoral cells (Figure S1); (b) comparison between the ${ }^{1} \mathrm{H}$ NMR spectra of intact MG-63 cells registered by HRMAS and by liquid state NMR, together with the spectrum of the suspension supernatant (Figure S2); and (c) effect of different NMR experiments (1D standard, CPMG, and diffusion edited) on the ${ }^{1} \mathrm{H}$ HRMAS NMR spectra mechanically lysed lung tumoral cells (Figure S3). This material is available free of charge via the Internet at http://pubs.acs.org.

Received for review March 16, 2009. Accepted April 30, 2009.

AC900545Q 